\title{
Perceived ease of use and usefulness of sustainability labels on apparel products: application of the technology acceptance model
}

\author{
Yoon Jin Ma*, Hae Jin Gam and Jennifer Banning
}

*Correspondence:
yjma@ilstu.edu
Illinois State University,
Normal, USA

Normal, USA

\begin{abstract}
This study explores consumers' perceptions of sustainability labels on apparel products and examines sustainability labels as an effective means of determining consumers' purchase intentions, using the technology acceptance model (TAM) as the foundation. Data were collected via self-administered web-based surveys from 903 randomly selected shoppers throughout the United States (U.S.). Findings validated that perceived ease of use, perceived usefulness, attitudes, and purchase intention were associated with consumers' use of sustainability labels. Within those four variables, sustainability label users exhibited significantly higher scores than non-label users, though the path relationships among those variables were not different between the two groups. This study is one of the first to use TAM to understand how consumers perceive and use sustainability labels for apparel products. Through this application, label reading behaviour is viewed similarly to how consumers use new informational sources for their decision making process. The findings provide practical implications for business marketers and managers of sustainability apparel products. As this study focused on sustainability labels and apparel product shopping among U.S. consumers, it may be limited to apply findings to other product categories and may be limited to consumers outside the U.S.
\end{abstract}

Keywords: Technology acceptance model, Sustainable, Apparel label, Sustainability

\section{Introduction}

Socially responsible consumption (SRC) is defined as consumers' purchase behaviours that (1) have a positive or less negative influence on the surrounding environment and/or (2) attempt to address social concerns (e.g., Francois-LeCompte and Roberts 2006; Mohr et al. 2001; Roberts 1995; Webster 1975), closely relating to social and environmental sustainability (Goworek et al. 2012). Common examples of SRC include buying products from companies that seek to help society, purchasing environmentally or socially sound products, and boycotting products from companies who fail to implement environmentally friendly business practices (Francois-LeCompte and Roberts 2006).

The textile and apparel industry is one industrial sector that generates detrimental impact on the environment, due to its excessive use of water, energy, pesticides, and

(c) The Author(s) 2017. This article is distributed under the terms of the Creative Commons Attribution 4.0 International License (http://creativecommons.org/licenses/by/4.0/), which permits unrestricted use, distribution, and reproduction in any medium provided you give appropriate credit to the original author(s) and the source, provide a link to the Creative Commons license, and indicate if changes were made. 
toxic chemicals in its production process and delivery to consumers (Walters et al. 2005). Socially unethical business practices have also been reported in the industry, as meeting highly unpredictable consumer demand for products and the risks involved in early commitment to large portions of their production far in advance becomes increasingly challenging (e.g., Catholic Online 2014; Minney 2011). Most apparel companies often seek to minimize costs of products through sourcing overseas (Ma et al. 2016; Wallace et al. 2012). Due to the complex nature of the apparel supply chain, labour violations such as working overtime, payment far less than minimum wage, and using child or forced labour have been observed in garment manufacturing facilities in less developed countries (Kunz and Garner 2011; Ma et al. 2016).

Efforts should therefore be made to address such problems and increase consumer demand for sustainable apparel products (Chen and Burns 2006; Nelliyat 2004). One barrier to this effort is that consumers experience challenges in identifying sustainable products and practices in the marketplace (Goswami 2008). An increased number of companies have added marketing claims focused on their environmentally responsible practices within product advertisements (Kim et al. 2012). Overall, however, sustainable practices related to apparel products are perplexing for general consumers to identify, due to the many aspects of production that need to be considered. From fibre and fabric production and garment manufacturing and finishing, to usage and disposal of the apparel products after use, the apparel life cycle is complicated (Chen and Burns 2006). This reality is further challenged by the more than 300 different sustainability labels being used in consumer products in general (Case 2009). While sustainability labels aid consumers in making responsible choices (Carrero and Valor 2012), the wide variety of sustainability labels present in the marketplace may become a barrier to SRC purchases if labels cannot be understood (D'Souza 2004; Horne 2009).

A variety of sustainability labels exist for textile and apparel products, but the labels have not experienced the same success as those in other product categories, such as organic food (Aspers 2008; Meyer 2001). The trend for fast-fashion and the lack of standardization in the industry may contribute to the failure for sustainability labelling to be widely adopted (Aspers 2008; Kunz and Garner 2011). Furthermore, the terms or technical jargon used in marketing claims for sustainability apparel products, such as all natural, organic, recyclable, and recycled, and the symbols and logos are sometimes too vague for consumers to understand without specific definitions included (Kim et al. 2012; Morris et al. 1995). Because term meanings on labels may vary by company, even with efforts by federal and state governments to standardize use of labelling terms, terms are often misinterpreted by consumers (Chen and Burns 2006). In summary, given complicated production processes, globalized production, and the variety of standards and certifications that are followed, little explanation and understanding make utilizing sustainability labels for apparel products very difficult. These factors raise the question whether or not consumers will expend time and effort to read sustainability labels, which in turn may influence their purchase decisions.

Taking into consideration that the textile and apparel industry makes a significant impact on the environment and that sustainability labels can enable consumers to make more environmentally and socially responsible purchasing decisions (D'Souza et al. 2006; Hyllegard et al. 2012), it is of critical importance to explore how consumers perceive 
current sustainability labels on apparel products and the influence of their perception on using sustainability labels in purchase decisions. To date, there has been limited research on the consumer perception of sustainability labels in the context of apparel shopping. Therefore, this study aimed to explore how consumers perceive sustainability labels and how this perception determines purchase intentions in their apparel product shopping. To accomplish this aim, the technology acceptance model (TAM) (Davis et al. 1989), which depicts the relationships of perceived ease of use (PEOU), perceived usefulness (PU), and attitudes (Att) with behavioural intention (BI), was applied and tested in order to understand consumers' sustainability label usage behaviour for apparel products. Within TAM as the theoretical framework, the objectives of this study were threefold: (1) to examine the effects of PEOU, PU, and Att with regard to sustainability labels on consumers' intention to buy (PI) apparel products with sustainability labels; (2) to compare the levels of PEOU, PU, Att, and PI between two consumer groups: those who have used sustainability labels and those who have never used sustainability labels; and (3) to compare the relationships among the research variables by two consumer groups. Understanding consumers' perception of sustainability labels may help to increase the use of sustainability labels in the market place, which in turn can encourage purchase of sustainable apparel products. Findings of this study can support the applicability of TAM to acceptance of an information media, consumers' sustainability label usage behaviours by empirically testing the validity of TAM within a non-technology based media.

\section{Literature review}

\section{Labelling for sustainable apparel products}

One of the mostly widely used promotional materials that highlight a company's environmental claims regarding its goods and services is sustainability labeling (Koos 2011). Labels such as trademarks and brand names are commonly used by sellers to assure a product or service's authenticity, which in turn helps buyers make more informed purchasing decisions (de Boer 2003). de Boer (2003) argued that labels' impact on consumer decision-making may vary depending on consumers' level of understanding, trust, and value of label claims. Labels of sustainability products will not always lead to an actual purchase of such products, but they will increase consumers' awareness of sustainable issues (Carrero and Valor 2012; Caswell 1997; de Boer 2003).

As a response to increasing demand from environmentally and socially conscious consumers, leaders in the textile and apparel industry have begun to apply sustainable business strategies, such as presenting sustainability labels or marketing claims at the point of sale (Etsy and Winston 2009; Marquardt 2010). Clothing hang tags and product packages are common places to display sustainability messages to communicate with consumers (Phau and Ong 2007). Studies examining the general effectiveness of sustainability labels and marketing claims on apparel products, recommend continued use of such labels. Hyllegard et al. (2012) examined the use of hang tags in advertising companies' sustainable practices and found that the use of hang tags containing detailed information and a third party logo increased participants' positive attitudes toward apparel brand and also influenced their patronage intentions. Similarly, work by Kim et al. (2012) advised that critical factors for marketers to include in sustainability messages were related to environmental concerns and knowledge, as well as social influences. 
The team employed environmental marketing claims (intrinsic versus extrinsic claims) as the moderating variables in their study that explored how norms and environmental concerns influence purchase intentions. While the extrinsic marketing claims involving social norms were more effective in influencing consumers' purchase intention, the intrinsic claims were more effective when personal environmental concerns were presented in the claims.

Specific claims included on sustainability labels have been explored as well; researchers have found that consumers respond differently to sustainability labels, depending on the claim being made. The "No Sweat" label, highlighting working conditions of the producer of a garment, encouraged purchase decisions for a small group of consumers (Dickson 2001). For that group of consumers, however, the sustainability label was more influential in the ultimate purchase decision than any other label information, including price, quality, colour, and fibre content. In a more recent study, consumers appeared to value environmental sustainability and animal welfare claims more than they did certified organic wool claims in a study about the efficacy of sustainability labels on wool gloves (Peterson et al. 2012).

While information contained in sustainability labels can help consumers and marketers alike, challenges exist. Consumers' increased interest in environmentally and socially friendly products has been predicted to be a precursor to the growth of sustainability labels in the marketplace (Case 2009), but the presence of multiple labels with unclear meanings can be challenging for consumers to interpret and may ultimately create a barrier to purchases. Consumers have reported confusion with the sustainability labels "EU Eco-Label," although the label had been supported with educational campaigns for many years (Horne 2009). Additionally, some consumers distrust the sustainability labels. British consumers expressed scepticism of fair trade clothing labels and asked for more objective, credible proof of environmentally and socially sound practices (Goworek et al. 2012).

These studies support the general use of sustainability labels but point to further questions to be answered if effectiveness is to be increased. A deeper understanding of impetuses for and intentions for consumers to purchase apparel with sustainability labels can help business marketers and managers tailor their sustainability messages in ways that will appeal to their target customer and encourage purchase.

\section{Theoretical foundation: technology acceptance model}

To explore fundamental preconditions for the use of sustainability labels in purchase decision making, the technology acceptance model (TAM) developed by Davis et al. (1989) was employed as the theoretical framework. TAM was derived from the theory of reasoned action (TRA) (Ajzen and Fishbein 1980; Fishbein and Ajzen 1975), which is a widely used model in social psychology studies. The TAM was specifically developed to address users' willingness to accept and use new technology or media in the field of information system management. Recently, TAM has been broadly applied to explain consumers' use of technology in the context of apparel shopping (e.g., Cho and Wang 2010; Kim et al. 2009; Kim and Forsythe 2008).

In TRA, the antecedents of a person's attitudes are behavioural beliefs and outcome evaluation. Davis et al. (1989) indicated that behavioural beliefs and outcome evaluation 
could not accurately measure an individual's acceptance of a new system as they are much influenced by various external factors (i.e., the system's technical design characteristics). Therefore, two self-efficacy perspective variables, perceived ease of use (PEOU) and usefulness (PU) were suggested as influential antecedents that shape users' attitudes (Att) and behavioural intention (BI) (Davis et al. 1989; Pavlou 2003). PEOU is defined as the degree to which individuals perceive how easy it is to use the technology and PU refers to the extent to which individuals believe how useful the technology would be (Davis et al. 1989). As illustrated in Fig. 1, TAM posits that both PEOU and PU influence the formation of favourable Att associated with the use of technology, which, in conjunction with PU, generate individuals' greater BI to use the technology. In addition, PEOU is expected to have a positive influence on individuals' perceptions regarding the usefulness of the technology (Davis et al. 1989).

Technology acceptance model with or without modifications, has been successfully applied to a wide range of empirical studies to predict and explain acceptance and adoption of a variety of technologies such as electronic banking (e.g., Al-Smadi 2012), mobile education (e.g., Tan et al. 2012) and social networks (e.g., Pinho and Soares 2011; Shin and Kim 2008), as well as to understand consumer markets for technological products and services such as online shopping (e.g., Vijayasarathy 2004) and mobile shopping (e.g., Kim et al. 2009). As depicted in the TAM, the relationships among PEOU, PU, Att, and BI have gained empirical support from numerous studies (e.g., Al-Smadi 2012; Kim et al. 2009; Shin and Kim 2008). Shin and Kim (2008) confirmed that PEOU and PU are critical antecedents of Att and BI in the context of adoption of social media technology. Likewise, Tan et al. (2012) found the significant linkage between PEOU and PU in mobile learning usage. Both variables in turn influenced BI to adopt the mobile learning technology. However, the results for the influence of PU on BI have been mixed. In a study about consumer's BI to use on-line shopping, Vijayasarathy (2004) found that PEOU and PU significantly predicted Att, which in turn determined BI to use on-line shopping. However, PU of on-line shopping did not explain BI. Similarly, Pinho and Soares (2011) revealed no empirical support between PU and BI in the context of adoption of social networks.

The adoption of new media for purchasing new products shares similarities with the adoption of new technology for decision making. As with new technology, a new product must have PEOU and PU to the intended consumer. These antecedents shape users'

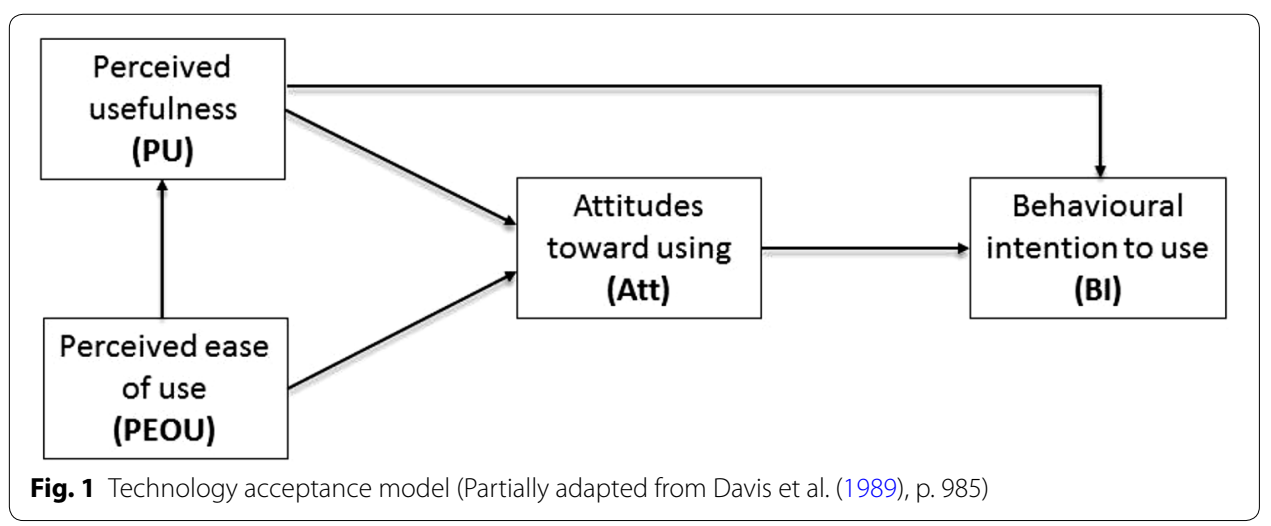


Att and BI towards the new product. In a study of an application of TAM, Benamati and Rajkumar (2002) applied the TAM to a non-technology based context, outsourcing decisions. In their study, TAM was successfully applied to organizational level decisions. Furthermore, the applicability of TAM to a non-technology context of outsourcing decisions was validated and confirmed in their later study (Benamati and Rajkumar 2008). In particular, as argued by Benamati and Rajkumar (2002), TAM was based on TRA, which has been extensively used in a wide range of consumer studies that depict the relationships between attitudes and intentions, in that it may be plausible to apply TAM to consumers' label acceptance behaviours. It is for this reason that we tested and validated the TAM in the context of consumers' use of sustainability labels to further explore the influences on the use of sustainability labels for apparel products. When consumers perceive that it is easy to read sustainability labels and find usefulness in making an informed sustainability purchase decision by understanding the meaning of terms and/ or symbols in the label, it is presumable to expect more use of sustainability labels, and subsequently more purchases of sustainable products.

\section{Research objectives and hypotheses development}

The purpose of this study is to empirically apply and test the TAM as a basis to explain how PEOU and PU are associated with consumer's Att toward use of sustainability label and PI. This study also identifies whether consumers who currently use sustainability labels ("label users") as part of purchasing decisions exhibit higher PEOU, PU, Att, and PI than non-users. In this study, sustainability label users are defined as those who have used a sustainability label when they shop. Lastly, this study investigates whether or not the different path relationships exist between sustainability label users and non-users in regard to their acceptance of sustainability labels.

Reading information on a sustainability label requires some level of understanding as the labels often present technical terms and/or symbols, and it is often challenging to process the information with the overuse of technical jargon and/or symbols (Baker 2002). Empirical studies reported that consumers have struggled with understanding information on the different types of sustainability labels in making a responsible purchase (D'Souza 2004; Horne 2009). Therefore, it would be meaningful to explore the role of PEOU in the context of sustainability label usage behaviours, positing the following hypotheses:

H1a PEOU of using sustainability label will have a positive influence on PU.

H1b PEOU of using sustainability label will have a positive influence on Att.

The purpose of using sustainability labels is to highlight a company's environmental and social responsibility claims regarding its goods and services. Consumers "tend to use or not use an application to the extent they believe it will help them perform their job better" (de Boer, p. 320), thus consumers will not read (or pay attention to) a sustainability label unless they see the benefit of using it. Therefore, the following hypotheses were posited:

H1c PU of using sustainability label will have a positive influence on Att.

H1d PU of using sustainability label will have a positive influence on PI.

A person's attitudes, which are built by past experiences, concerns, information and social pressures, influence the person's behaviour (Fishbein and Ajzen 1975). Numerous 
studies suggest that an individual's positive attitudes toward certain products greatly influence their purchase intention (behaviour). This study explores whether a favourable Att toward a sustainability label will positively influence the PI of products with that label, generating the following hypothesis:

H1e Att of using sustainability label will have a positive influence on PI.

Previous studies (Dickson 2001; Gam et al. 2014) indicate that consumers who are more likely to purchase sustainability-labelled products exhibit different characteristics than those who are not. Findings showed that a consumer's previous usage or purchasing experiences are the strongest indicator of an actual purchase. The previous usage or experiences may influence consumers' self-efficacy perceptions regarding utility and competence when using such products. Therefore, this study explores whether consumers who already used sustainability label on apparel products possess different beliefs of PEOU and PU, Att, and PI regarding the sustainability labels. In a study about statistical program usage among college students (Yi et al. 2006), individuals' differences such as prior experience with computers had significant impact on their usage behaviours. In that, this study also explores whether there are different adoption processes existing between two user groups. Thus, the following hypotheses were posited:

H2a Sustainability label users will have higher levels of PEOU with sustainability labelled apparel products.

H2b Sustainability label users will have higher levels of PU with sustainability labelled apparel products.

H2c Sustainability label users will have higher levels of Att with sustainability labelled apparel products.

H2d Sustainability label users will have higher levels PI with sustainability labelled apparel products.

H3a Sustainability label users will have different relationships between PEOU and PU from those of sustainability label non-users.

H3b Sustainability label users will have different relationships between PEOU and Att from those of sustainability label non-users.

H3c Sustainability label users will have different relationships between PU and Att from those of sustainability label non-users.

H3d Sustainability label users will have different relationships between PU and PI from those of sustainability label non-users.

H3e Sustainability label users will have different relationships between Att and PI from those of sustainability label non-users.

\section{Methods}

\section{Sample and data collection}

Using a web-based survey, approximately 10,000 randomly selected nation-wide shoppers in the United States (U.S.) were invited through a U.S. independent marketing research company to participate in this study. The modified method for web-based survey design by Dillman et al. (2009) was employed to collect data; an initial invitation e-mail letter with a hyperlink to a website for the survey, as well as a reminder, was sent out to participants during a 10-day period in summer 2013. 
A total of 1657 respondents participated in the survey, resulting in a response rate of $16.6 \%$. After deleting responses with significant amounts of missing values and those without a purchase experience, 903 responses from participants who had purchased a sustainable product previously were deemed usable for data analysis. The reason we used the data only from those who had a previous purchase experience of a sustainable product is that PEOU and PU in our model were measured based on their purchase experience of a general sustainable product. A majority of the respondents had used sustainability labels when they shopped (71.8\%), while about $28 \%$ never used sustainability labels during their shopping. The top five most purchased items with sustainability labels were food (72.1\%), cleaning products (54.7\%), electronics (47.2\%), energy (41.2\%), and health and beauty products (28.3\%). The age of the respondents ranged from 18 to 84 years with the mean age of 44.6 years. A majority of participants were white or European American (79.7\%), married (51.1\%), employed (56.1\%), and female (54.1\%). Nearly $30 \%$ earned a four-year college degree, followed by some college education (28.2\%), and a master's degree (12.9\%). A majority of the respondents earned \$25,000-49,999 (28.6\%) and \$50,000-74,999 (24.2\%). Approximately $30 \%$ had purchased apparel products four to six times during the past 12 months. On average, respondents had spent approximately $\$ 877$ on apparel products during the past 12 months.

Under the assumption that characteristics of later respondents are close to those of non-respondents (Armstrong and Overton 1977), non-response bias was assessed by comparing demographic characteristics of early $20 \%$ respondents and late $20 \%$ respondents. The results from Chi square tests revealed no statistically significant differences in demographic characteristics, except for employment at $p<.05$. In the early respondent group, there were more currently employed respondents than the late respondent group, while more retired respondents were found in the late responses than in the early responses $(p<.05)$. Table 1 summarizes the demographic characteristics of the sample.

\section{Instrument development and data analysis}

The web-based questionnaire consisted of six sections: PEOU, PI, Att, and PI of a sustainability labelled apparel product, and demographic characteristics. To assess consumers' PEOU of sustainability labels in making a purchase decision, eight items were modified from previous studies (Davis et al. 1989; Vijayasarathy 2004). Another eight items were adapted from Davis et al. (1989) and Vijayasarathy (2004) to measure PU of sustainability labels. These scales were modified to measure such variables in the situation of sustainability labels and purchase decisions of sustainable products. Some sample questions include, "I would find it easy to use sustainability labels to make a purchase decision" for PEOU and "sustainability labels give (will give) me access to useful shopping information" for PU. The five items capturing consumers' overall Att toward sustainability labels were adopted and modified from Beltramini (1988) and Vijayasarathy (2004). In order to assess consumers' intention to buy apparel items with a sustainability label, five sustainability labels that are currently available on apparel products in the U.S. market were incorporated to PI items (Targosz-Wrona 2009). PEOU, PU, and PI items were measured on a 7-point Likert-scale, 1 being "strongly disagree" and 7 being "strongly agree" or 1 being "very unlikely" and 7 being "very likely". Att items were measured on a 5-point differential semantic scale. The questions are presented on Table 2. 
Table 1 Sample characteristics

\begin{tabular}{|c|c|c|}
\hline Characteristics & Frequency & Percentage (\%) \\
\hline \multicolumn{3}{|l|}{ Gender } \\
\hline Male & 413 & 45.9 \\
\hline Female & 487 & 54.1 \\
\hline \multicolumn{3}{|l|}{ Sustainability label } \\
\hline Have used when shopping & 648 & 71.8 \\
\hline Never used when shopping & 255 & 28.2 \\
\hline \multicolumn{3}{|l|}{ Age (years) } \\
\hline $18-24$ & 116 & 12.9 \\
\hline $25-44$ & 326 & 36.1 \\
\hline $45-59$ & 264 & 29.2 \\
\hline $60-84$ & 196 & 21.7 \\
\hline 85 and older & 0 & 0 \\
\hline \multicolumn{3}{|l|}{ Ethnicity } \\
\hline White or European & 720 & 79.7 \\
\hline Asian American & 43 & 4.8 \\
\hline Black or African American & 61 & 6.9 \\
\hline Hispanic or Latino & 36 & 4.0 \\
\hline Native American & 4 & .4 \\
\hline Native Hawaiian or Pacific Islander & 3 & .3 \\
\hline Mixed/bi-racial & 20 & 2.2 \\
\hline Others & 15 & 1.7 \\
\hline \multicolumn{3}{|l|}{ Employment } \\
\hline Employed & 495 & 56.1 \\
\hline Not employed & 233 & 26.4 \\
\hline Retired & 155 & 17.6 \\
\hline \multicolumn{3}{|l|}{ Education } \\
\hline Less than high school & 4 & .4 \\
\hline High school or GED & 131 & 14.6 \\
\hline Some college & 254 & 28.2 \\
\hline 2 year associate degree & 95 & 10.6 \\
\hline 4 year college degree & 266 & 29.6 \\
\hline Master's degree & 116 & 12.9 \\
\hline Doctoral degree & 15 & 1.7 \\
\hline Professional degree & 19 & 2.1 \\
\hline \multicolumn{3}{|l|}{ Marital status } \\
\hline Single & 272 & 30.5 \\
\hline Married & 456 & 51.1 \\
\hline Separated & 21 & 2.4 \\
\hline Divorced & 105 & 11.8 \\
\hline Widowed & 38 & 4.3 \\
\hline \multicolumn{3}{|l|}{ Family household income before tax } \\
\hline Less than $\$ 10,000$ & 42 & 4.7 \\
\hline$\$ 10,000$ to $\$ 24,999$ & 120 & 13.5 \\
\hline$\$ 25,000$ to $\$ 49,999$ & 254 & 28.6 \\
\hline$\$ 50,000$ to $\$ 74,999$ & 215 & 24.2 \\
\hline$\$ 75,000$ to $\$ 99,999$ & 121 & 13.6 \\
\hline$\$ 100,000$ to $\$ 149,999$ & 101 & 11.4 \\
\hline$\$ 150,000$ and over & 36 & 4.0 \\
\hline
\end{tabular}


Table 2 Confirmatory factor analysis and measurement model results for model constructs

\begin{tabular}{|c|c|c|c|c|c|}
\hline Variables & Factor items & $\begin{array}{l}\text { Factor loadings } \\
{\text { (t value })^{\mathrm{a}}}\end{array}$ & Cronbach's alpha & $\mathrm{CR}^{\mathbf{b}}$ & AVE \\
\hline \multirow[t]{4}{*}{$\begin{array}{l}\text { Perceived ease of use } \\
\text { (PEOU) }\end{array}$} & $\begin{array}{l}\text { Learning to utilize } \\
\text { sustainability labels } \\
\text { was (would be) easy } \\
\text { for me }\end{array}$ & $.82^{\mathrm{d}}$ & .90 & .958 & .740 \\
\hline & $\begin{array}{l}\text { I would find it easy to } \\
\text { use sustainability } \\
\text { labels to make a pur- } \\
\text { chase decision }\end{array}$ & $.86(30.70)$ & & & \\
\hline & $\begin{array}{l}\text { It would be easy for me } \\
\text { to become an expert } \\
\text { at utilizing sustainabil- } \\
\text { ity labels }\end{array}$ & $.82(28.35)$ & & & \\
\hline & $\begin{array}{l}\text { Overall, I find sustain- } \\
\text { ability labels easy to } \\
\text { utilize }\end{array}$ & .85 (29.98) & & & \\
\hline \multirow[t]{8}{*}{$\begin{array}{l}\text { Perceived usefulness } \\
\text { (PU) }\end{array}$} & $\begin{array}{l}\text { Sustainability labels give } \\
\text { (will give) me access } \\
\text { to useful shopping } \\
\text { information }\end{array}$ & $.88^{\mathrm{d}}$ & .96 & .903 & .700 \\
\hline & $\begin{array}{l}\text { Sustainability labels are } \\
\text { (will be) useful to me }\end{array}$ & $.93(43.88)$ & & & \\
\hline & $\begin{array}{l}\text { Sustainability labels } \\
\text { make (will make) } \\
\text { purchasing easier }\end{array}$ & $.89(39.45)$ & & & \\
\hline & $\begin{array}{l}\text { Sustainability labels } \\
\text { make (will make) me a } \\
\text { smarter shopper }\end{array}$ & $.90(40.69)$ & & & \\
\hline & $\begin{array}{l}\text { Sustainability labels are } \\
\text { (will be) very beneficial } \\
\text { to me }\end{array}$ & $.93(43.81)$ & & & \\
\hline & $\begin{array}{l}\text { Purchase decision of SR } \\
\text { products would be dif- } \\
\text { ficult to make without } \\
\text { sustainability labels }\end{array}$ & $.69(24.98)$ & & & \\
\hline & $\begin{array}{l}\text { Utilizing sustainability } \\
\text { labels reduces the } \\
\text { time I spend on shop- } \\
\text { ping }\end{array}$ & $.72(26.46)$ & & & \\
\hline & $\begin{array}{l}\text { Overall, I find sustain- } \\
\text { ability labels useful } \\
\text { in making purchase } \\
\text { decisions }\end{array}$ & $.91(41.61)$ & & & \\
\hline \multirow[t]{5}{*}{$\begin{array}{l}\text { Attitude toward sustain- } \\
\text { ability label use (Att) }\end{array}$} & $\begin{array}{l}\text { Unbelievable-Believ- } \\
\text { able }\end{array}$ & $.90^{\mathrm{d}}$ & .94 & .946 & .777 \\
\hline & $\begin{array}{l}\text { Untrustworthy-Trust- } \\
\text { worthy }\end{array}$ & $.91(42.80)$ & & & \\
\hline & $\begin{array}{l}\text { Not convincing-Con- } \\
\text { vincing }\end{array}$ & $.90(42.23)$ & & & \\
\hline & Not credible_Credible & $.91(43.52)$ & & & \\
\hline & $\begin{array}{l}\text { Questionable-Unques- } \\
\text { tionable }\end{array}$ & $.78(31.29)$ & & & \\
\hline
\end{tabular}


Table 2 continued

\begin{tabular}{|c|c|c|c|c|c|}
\hline Variables & Factor items & 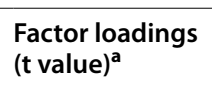 & Cronbach's alpha & $\mathrm{CR}^{\mathbf{b}}$ & AVE $^{\mathrm{C}}$ \\
\hline \multirow[t]{6}{*}{$\begin{array}{l}\text { Purchase intention of a } \\
\text { sustainability labelled } \\
\text { apparel product (PI) }\end{array}$} & $\begin{array}{l}\text { How would you be willing } \\
\text { to buy apparel products } \\
\text { with this label? }\end{array}$ & & .92 & .916 & .687 \\
\hline & $\begin{array}{l}\text { EU eco-label (the Flower) } \\
\text { by European Com- } \\
\text { mission }\end{array}$ & $.82^{\mathrm{d}}$ & & & \\
\hline & $\begin{array}{l}\text { Green seal-certification } \\
\text { by Green Seal organi- } \\
\text { zation }\end{array}$ & $.87(31.12)$ & & & \\
\hline & $\begin{array}{l}\text { EKO Sustainable Textile } \\
\text { certification by Global } \\
\text { Organic Textile } \\
\text { Standard International } \\
\text { Working Group }\end{array}$ & $.86(30.68)$ & & & \\
\hline & $\begin{array}{l}\text { Fair Trade certification } \\
\text { by Fair Trade USA } \\
\text { organization }\end{array}$ & $.77(26.36)$ & & & \\
\hline & $\begin{array}{l}\text { Global Organic Textile } \\
\text { Standard by Global } \\
\text { Organic Textile } \\
\text { Standard International } \\
\text { Working Group }\end{array}$ & $.83(29.27)$ & & & \\
\hline \multicolumn{6}{|c|}{ CFA model fit $x^{2}=994.93, d f=203, x^{2} / d f=4.90, p<.001, \mathrm{GFI}=.91, \mathrm{CFI}=.96, \mathrm{IFI}=.96, \mathrm{NFI}=.95, \mathrm{SRMR}=.03, \mathrm{RMSEA}=.06$} \\
\hline \multicolumn{6}{|c|}{$\begin{array}{l}{ }^{\mathrm{b}} \text { Composite reliability }(\mathrm{CR}) \text { is calculated as }(\Sigma \text { standard loading })^{2} \text { divided by }(\Sigma \text { standard loading })^{2}+\Sigma \varepsilon_{\mathrm{j}} \text {. The measurement } \\
\text { error, } \varepsilon_{\mathrm{j}} \text { is calculated as }\left(1.0-(\text { standard loading })^{2}\right)(\text { Hair et al. 1998) }\end{array}$} \\
\hline
\end{tabular}

Demographic background and general behaviours in regard to sustainability labels were asked. A brief description of sustainability labelling (see Appendix) was provided to respondents prior to the first question to assure their understanding of the term, "sustainability labelling", used in the survey. To divide participants into sustainability label users and non-users, general sustainability label usage behaviour was asked with the question "have you ever used a sustainability label when you shop". "Non sustainability label users" refers to someone who buys sustainable products, but who does not use sustainability labels to do so. Prior to collecting data, a pilot test was conducted with potential respondents, a small size of consumer group, to improve the clarity of the scales and instructions as well as the format of the overall survey, and necessary corrections were made. The data were statistically analysed using SPSS 21.0 and AMOS 21.0. The following statistical analyses were conducted: descriptive analysis, principal component analysis, internal reliability, confirmatory factor analysis, correlations, independent samples $t$-tests, path analysis, and multi-group comparison.

\section{Results and discussion}

\section{Exploratory factor analysis and internal reliability}

In order to determine dimensionality of measurements with multiple items, principal component analysis with varimax rotation was performed. Constructs with the factor loadings of items above .55 and not higher than .30 on the other factors were considered 
valid (Kline 2014; Nunnally et al. 1967). All research constructs (i.e., PEOU, PU, Att, PI) appeared as a single dimension with high factor loadings (.74 to .93) and high percent of variance explained (74.8-82.0\%). PEOU associated with sustainability label was extracted to a single dimension after deleting four items with lower factor loadings and reliability scores. In the principal component analyses, the varimax rotation using orthogonal rotation methods was used instead of those with the oblique rotation because the orthogonal rotation methods assume the factors are uncorrelated, while the oblique rotation methods assume the correlation among the factors in the analysis (Gorsuch 1983). As shown in the results of EFA, all four variables have a single dimension, therefore the varimax rotation method was deemed appropriate for the current study.

Internal reliability of each measurement was also evaluated through Cronbach's standardized alpha values; when the alpha values were above .70, the items were remained for further analysis (Cronbach 1951). The Cronbach's alpha scores of those four research variables ranged from .90 to .96 , indicating strong internal consistency of measures (see Table 2). Means of summated multiple item measures were computed and used to represent model constructs for further analysis.

\section{Confirmatory factor analysis and scale validity}

Scale validities were assessed by confirmatory factor analysis (CFA) using AMOS 21.0. To confirm the dimension of four research variables identified in exploratory factor analysis (EFA), the measurement model of 22 observed variables and four latent variables was examined. The overall fit of the model to the data was evaluated through Chi square statistics, goodness-of-fit index (GFI), comparative fit index (CFI), normed fit index (NFI), incremental fit index (IFI), standardized root mean square residual (SRMR), and root mean square error of approximation (RMSEA). A better fit of the model has a smaller Chi square value; however, when the sample size is larger than 200, the Chi square statistic is known to be sensitive to the sample size (Bagozzi and Yi 1988; Kline 2005). To reduce the effect of sample size, the normed Chi square $\left(x^{2} / d f\right)$ can also be used to assess overall model fit when large samples are used, and a recommended acceptable ratio for this statistic is 2.0, 3.0, or even as high as 5.0 (Marsh and Hocevar 1985; Wheaton et al. 1977). By convention, the following guidelines are considered as an indicator of good model fit to the data: GFI, CFI, NFI, IFI > .90 (Meyers et al. 2006), SRMR $<.08(\mathrm{Hu}$ and Bentler 1999), and RMSEA < .07 (Steiger 2007). In particular, Hu and Bentler (1999) suggested the two-index presentation strategy and combinational rules of CFI of .96 or higher and SRMR of .09 or lower as an indicator of good-fit model. The statistical significance of parameter estimates were evaluated using $t$ values.

The test of the measurement model yielded a $x_{(203)}^{2}$ value of 994.93 and a $x^{2} / d f$ of 4.90 $(p<.001)$. The Chi square value of the measurement model indicated a lack of satisfactory fit to the sample data, but the normed Chi square value was within the acceptable rage. Other fit indices of GFI $=.91$, CFI $=.96, \mathrm{NFI}=.95$, IFI $=.96$, SRMR $=.03$, RMSEA $=.06$ indicated that the model produced a good fit to the data. Particularly, the CFI value of .96 and SRMR value of .03 were within the acceptable fit parameters of $\mathrm{Hu}$ and Benter's two-index presentation strategy (Hu and Bentler 1999). All standardized factor loadings in the model ranged from .69 to .93 and were statistically significant at $p<.001$ (see Table 2). 
Composite reliability values for all four variables were calculated as guided by Fornell and Larcker (1981). As shown in Table 2, the composite reliability values ranged from .903 to .958 , which were higher than a commonly recommended value of .70 for construct reliability (Hair et al. 1998), indicating that all constructs in the measurement model provided evidence of good reliable measures. With regard to the convergent validity, the average variance extracted (AVE) values were calculated (Hair et al. 1998). The values for four constructs ranged from .687 to .740 and they were all above .5, a threshold value for convergent validity (Fornell and Larcker 1981), suggesting reasonable overall convergent validity of the constructs.

Furthermore, the discriminant validity was assessed through the AVE values and constructs' correlation. Fornell and Larker (Fornell and Larcker 1981) suggested that the AVE value greater than the squared value of the construct's correlations with the other constructs is the evidence of discriminant validity. As shown on Table 3, the correlations of paired constructs ranged from .59 to .76 , generating the squared values of the correlations of .35 to .58. These squared values do not exceed the AVE values of those constructs that ranged from .687 to .740 , providing the good evidence of the discriminant validity of all four constructs in the model.

\section{Path model analysis: model testing}

The TAM model in the context of sustainability label use consisting of one exogenous variable (PEOU) and three endogenous variables (PU, Att, PI) was tested by path analysis with the maximum-likelihood estimation procedure using AMOS 21.0. Descriptive statistics and correlations among research constructs for the path model are shown in Table 3 .

The results of the path model analysis revealed acceptable overall fit indices: a Chi square of 24.60 with degrees of freedom of 1 ( $p<.001)$, GFI of .99, CFI of .99, NFI of .99 , IFI of .99 , and SRMR of .025. The standardized path coefficients and associated $t$-values for each relationship as well as squared multiple correlations $\left(R^{2}\right)$ for each endogenous variable were shown in Fig. 2. All of the paths in the model were significant, with the standardized path coefficients ranging from .21 to $.76(p<.001)$. There were significant effects of PEOU to PU (H1a) and Att toward use of sustainability label (H1b). PU had a significantly positive influence on Att (H1c) and PI (H1d). Furthermore, a positive effect of Att toward use of sustainability labels on PI was also observed (H1e). Therefore, H1a, H1b, H1c, H1d, and H1e were statistically supported. These findings revealed that those who were comfortable using sustainability labels were more likely to perceive

Table 3 Descriptive statistics and correlation matrix of model constructs

\begin{tabular}{|c|c|c|c|c|c|c|}
\hline \multirow[t]{2}{*}{ Variables } & \multicolumn{6}{|c|}{ Correlations } \\
\hline & Mean & SD & 1 & 2 & 3 & 4 \\
\hline Perceived ease of use of sustainability label (PEOU) & 4.84 & 1.27 & - & - & & \\
\hline Perceived usefulness of sustainability label (PU) & 4.90 & 1.37 & $.76^{* *}$ & & & \\
\hline Attitudes toward use of sustainability label ${ }^{a}$ (Att) & 3.68 & .91 & $.66^{* *}$ & $.75^{* *}$ & - & \\
\hline Intention to buy apparel products with a sustainability label (PI) & 4.83 & 1.19 & $.59^{* *}$ & $.64^{* *}$ & $.59^{* *}$ & - \\
\hline
\end{tabular}

${ }^{* *} p<.01$; all variables but ${ }^{\text {a }}$ were measured on a 7-point Likert scale; ${ }^{\text {a }}$ were measured on a 5 -point differential semantic scale 


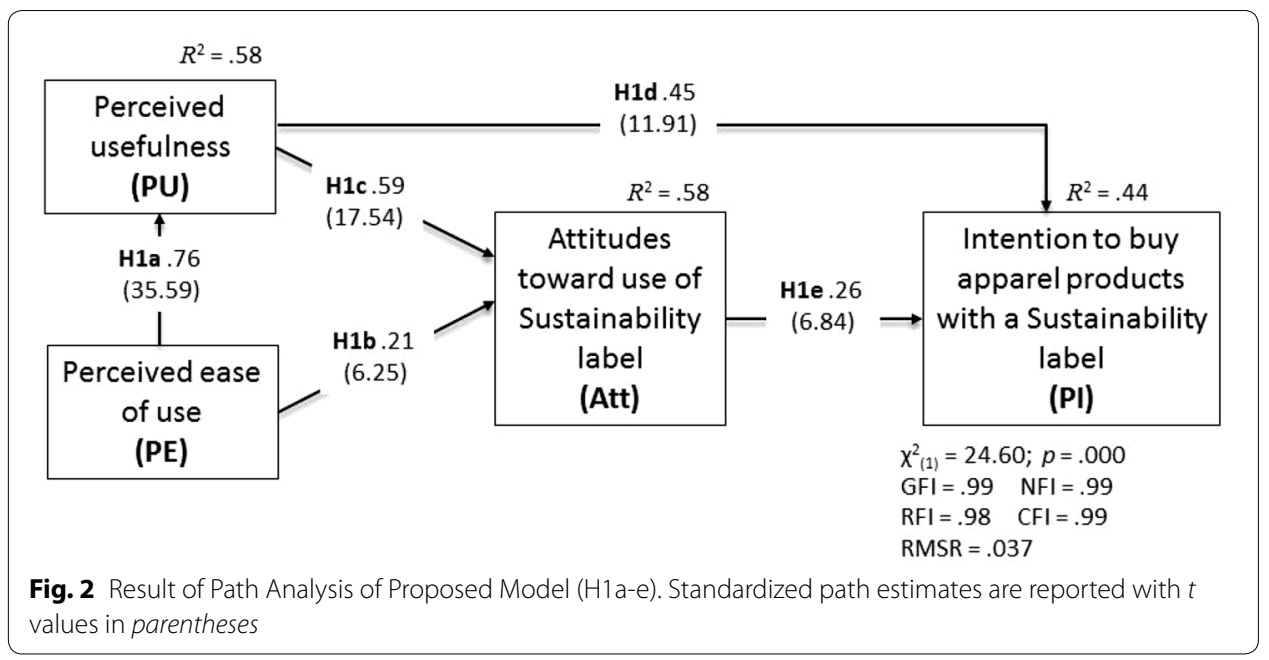

their usefulness and hold favourable attitudes toward the use of the label. Similarly, consumers who found sustainability labels useful tended to have a more positive Att. Consumers' favourable Att also determined greater willingness of purchasing a sustainability labelled apparel product, confirming the study conducted by Norberg et al. (2011). Likewise, those who perceived more usefulness were also likely to have a greater willingness to buy a sustainability labelled apparel products.

\section{Comparison of sustainability label usage factors between label users and non-users}

Sustainability label users and non-users were identified based on their experiences with sustainability labels. Sustainability label users $(71.8 \%)$ are those who have used sustainability label when they shop and non-users $(28.2 \%)$ are those who never used the label. A series of independent samples $t$ tests were performed to examine differences between sustainability label users and non-users in their PEOU, PU, Att, and PI with a sustainability labelled apparel product. The results revealed that there were statistically significant differences in all levels of PEOU $(t=8.13, p<.001)(\mathrm{H} 2 \mathrm{a}), \mathrm{PU}(\mathrm{H} 2 \mathrm{~b})(t=7.13$, $p<.001)$, Att $(\mathrm{H} 2 \mathrm{c})(t=6.44, p<.001)$, and PI of the respondents $(\mathrm{H} 2 \mathrm{~d})(t=6.36$, $p<.001$ ) depending on whether they have used sustainability labels before (sustainability label users) or not (sustainability label non-users) (see Table 4). Therefore, H2a, H2b, $\mathrm{H} 2 \mathrm{c}$, and $\mathrm{H} 2 \mathrm{~d}$ were statistically supported. Those who previously had used sustainability

Table 4 Independent samples $t$-tests for comparison of means

\begin{tabular}{|c|c|c|c|c|c|}
\hline \multirow[t]{2}{*}{ Variables } & \multicolumn{2}{|c|}{ SR label users $(n=648)$} & \multicolumn{2}{|c|}{ SR label non-users $(n=255)$} & \multirow[t]{2}{*}{$t$ value } \\
\hline & Mean & SD & Mean & SD & \\
\hline Perceived ease of use (H2a) & 5.04 & 1.21 & 4.30 & 1.27 & $8.13^{* * *}$ \\
\hline Perceived usefulness (H2b) & 5.10 & 1.30 & 4.40 & 1.43 & $7.13^{* * *}$ \\
\hline Attitudes $^{\mathrm{a}}(\mathrm{H} 2 \mathrm{C})$ & 3.80 & .85 & 3.35 & .98 & $6.44^{* * *}$ \\
\hline Intention (H2d) & 4.99 & 1.14 & 4.44 & 1.24 & $6.36^{* * *}$ \\
\hline
\end{tabular}


labels when they shopped were likely to perceive the labels as more useful, easier to understand, hold more positive Att toward use of sustainability labels, and had greater PI associated with apparel products with such labels.

\section{Group comparison: sustainability label users vs. non-users}

The path relationships in the model were compared based on the identified differences in factors determining sustainability label usage behaviours through $t$-tests in $\mathrm{H} 2 \mathrm{a}-\mathrm{d}$. In order to identify potential differences in the path estimates of the proposed model between sustainability label users and non-users, the multi-group comparison technique was utilized. First, the path model was estimated across the sustainability label user sample and the non-user sample at the same time and without a constraint, allowing free estimation of path coefficients in the model across the two samples (i.e., unconstrained model). The Chi square value for the unconstrained model was 22.72 with $d f=2$. Next, the model was re-estimated across each sustainability user and non-user sample, by constraining the path estimated to be equal (i.e., constrained model), revealing the Chi square value of 29.68 with $d f=7$. Finally, the Chi square difference statistic $\left(\Delta x^{2}\right)$ in changing degrees of freedom was examined to identify invariance of the model fit between constrained and unconstrained models (Byrne 2004; Kline 2005). As shown on Table 5, the results revealed that the differences in the path estimates between sustainability users and non-users were not significant (H3a-d) $\left(\Delta \mathrm{X}^{2}=6.96, \Delta d f=5 ; p=.224\right)$, thus H3a, H3b, H3c, and H3d were rejected. These findings suggest that the relationships between PEOU and PU, PEOU and Att, PU and PI, and Att and PI were not different whether they are sustainability label users or not, indicating sustainability label adoption model for apparel product is invariant regardless of their previous experience of sustainability label experience.

\section{Conclusions and implications}

Sustainable practices in the apparel industry are evolving, making it critical to assist consumers with sustainable purchases through effective tools and education. Sustainability labels can be an ideal communication tool when consumers notice and use the information on the labels. The use of sustainability labels for apparel products, however, has not been fully explored. Therefore, the current study has unique contributions to the limited body of research on sustainability label usage behaviours of apparel product consumers, with implications for marketers and managers.

This study approached label reading behaviour as a process of using a new media for the decision making process. As such, TAM (Davis et al. 1989) was applied and tested to the research context of sustainability labels by viewing label using behaviour as similar to

Table 5 Chi square difference statistic for multi-group comparisons (H3a-e)

\begin{tabular}{llcc}
\hline Model & $\mathbf{x}^{\mathbf{2}}$ & $\boldsymbol{d f}$ & $\boldsymbol{p}$ \\
\hline Unconstrained & 22.72 & 2 & .000 \\
Constrained (all paths to be equal) & 29.68 & 7 & .000 \\
\hline Difference & $\boldsymbol{\Delta \mathbf { x } ^ { \mathbf { 2 } }}$ & $\boldsymbol{\Delta d f}$ & $\boldsymbol{p}$ \\
\hline In values between the models & 6.96 & 5 & .224 \\
\hline
\end{tabular}


the way consumers use new sources of technology. The selection of this model is appropriate as two specific beliefs in TAM, PEOU and PU, were explored to see how they determine consumer Att and PI associated with sustainability labelled apparel products. The TAM model suggests that PU and PEOU are preceding variables to increase the efficacy of the label. Consumers today often experience information "overload," which can influence purchase decisions in both positive and negative ways, depending on the context. Acquiring sustainability information on a label requires further effort in a consumer's thought process to purchase apparel products. As current criticisms of existing sustainability labelling include credibility, consistency and uniformity, understanding how consumers approach to sustainability labels as an information acquiring tool is vital.

Findings confirmed all paths in TAM, revealing that PEOU and PU are affirmative predictors of favourable Att toward the use of the label, which, in conjunction with PU, determined greater willingness to purchase a sustainability labelled apparel product. Consumers' self-efficacy related variables, such as how consumers perceive the sustainability labels that are often filled with technical symbols and jargons in terms of competence and usefulness, are significant to understand in order to comprehend and predict their responses on the labels for the purchase decision making process. A consumer will use sustainability labels when the labels are easy to understand and useful. The findings are also consistent with those of previous studies that examined the use of new technology in apparel shopping (Cho and Wang 2010; Kim et al. 2009; Kim and Forsythe 2008). Therefore, the new approach with TAM variables establishes an important contribution to the sustainability labelling in apparel products.

Perceived usefulness, in particular, had the largest positive impact on the consumers' Att toward sustainability label use and PI, respectively. PU is defined as a person's belief of benefits from using a particular system (Davis 1989). This result might be interpreted as whether a consumer's original desire for obtaining sustainability information is a critical antecedent in using a sustainability label. This study's findings imply that future directions in improving sustainability labels for apparel products should focus on motivation and incentive for using sustainability labels in making a purchase decision. This could be accomplished by increasing awareness of sustainability issues. Developing a "reading labels" for environment or person's wellbeing campaign and educating consumers of the benefits from using/reading information on sustainability labels can be recommended. As PEOU also impacts on the positive Att and PI, developing easy to read and informative sustainability labels by utilizing standardized systems for apparel products will be essential to appeal to a wide range of consumers.

This study examined the difference in adoption of sustainability labels for apparel products between sustainability label users and non-users. When a new technology is introduced, there are individuals who adopt the technology at the early stage; it is these early adopters who often support the use of innovations (Rogers 1983). In this study, it was found that sustainability label users demonstrated higher levels of PEOU, PU, Att, and PI of a sustainability labelled apparel product than those who have never used sustainability labels before. The results indicated that consumer's label usage experiences (i.e., sustainability label users vs. non-users) are related to their current label use and perceived ease of, Att toward and intentions to use sustainability labels. 
Finally, the relationships among the research variables in the path model were further compared between sustainability label users and non-users. Findings from multi-group path model comparison analysis revealed that the roles of PEOU and PU in determining Att and PI of a sustainability labelled apparel product were not different whether or not they were a sustainability label user. As discussed above, although they have different level of PEOU, PU, Att and PI across groups, there was no difference between sustainability label users and non-users in how those perceptions shaped Att and PI. Overall, the findings provide evidence of the applicability of TAM to this specific research context. Moreover, the model invariance provides empirical support for the critical roles that PEOU and PU of sustainability labels exhibited in shaping positive Att and greater PI of a sustainability labelled apparel product, whether they are active sustainability label users or not.

Findings of this study offer practical implications for business marketers and managers of sustainable apparel products. Both sustainability label users and non-users demonstrated the same approach process from perceptions to purchase intentions of sustainability labelled apparel products. This implies that whether or not a consumer is a sustainability label user, once they access the label and perceive it to be easy to read and useful, they are likely to utilize the information on the label. Therefore, this study suggests that marketers should also focus on the physical appearance of label as much as the contents of label. For example, marketers need to use more user-friendly terms such as using "made by" instead of using "ethical production" as it is a vague term to consumers and/or symbols on labels, and a design layout that consumers feel comfortable accessing. In addition, taking into consideration that non-users appeared to have lower levels of PEOU and PU from sustainability labelling than did sustainability label users, it is important to develop sustainable apparel labels that appeal to label non-users by enhancing practical aspects of the labels in that they can feel easy and useful from the labels. Therefore, an educational campaign encouraging consumers to read labels for purchasing sustainable products should be implemented. This suggestion confirms Beltramini's study (1988), which found that the warning information itself in the label of cigarettes had no significant effect on respondents' smoking behaviour. Rather, consumers exhibited higher belief toward warning labels that they had seen over time as they became familiar with labels. Further, their belief affected their attitude toward the hazards of smoking. Utilizing visual elements such as graphics or distinct colours may draw general consumers' attention and increase positive perceptions of the label information. In addition, utilizing communication technologies or techniques that are familiar to the target consumers would be an effective strategy. Implementing an educational campaign through a variety of social media platforms or using a commonly recognizable buzzword such as "eco chic" or "up-cycled fashion" on sustainability labels may attract young adult non-users.

This study applied and tested TAM to understand sustainability label usage behaviours for apparel products. A nation-wide random sample of U.S. general consumers was used, and participants were filtered by whether or not they had purchased sustainable products previously. The findings are thus limited to U.S. consumers and may not apply to non-sustainability consumers. In order to enhance the generalizability, it is necessary to validate the model with non-sustainable product consumers and consumers in 
other countries and cultures. Despite similarity within most demographic characteristics of early respondents and late respondents, current employment status exhibited the significant difference in the non-response bias test. Therefore, a possible response bias may need to be considered in respondents' employment status. Furthermore, future studies may extend the sustainability label adoption model by including other external variables that may influence consumers' perception of the labels such as self-efficacy and knowledge regarding sustainability labels in general and/or for apparel products. Adding consumers' sustainable consumption behaviours and social influence to the model is recommended as well. The current study tested the model invariance across groups, sustainability label users and non-users. A moderating or mediating effect of being a label user, such as age or knowledge level related to sustainable products, should be explored in a future research. It would also be meaningful to investigate why consumers adopt sustainable apparel labels by identifying expected benefits from their use. This study focused on sustainability labels and apparel product shopping, thus the findings may not be applied to other product categories.

Authors' contributions

YM developed the conceptual approach as well as analyzed data. YM and HG developed the literature review and conducted data collection. YM, HG, and JB developed the results and conclusion. All of the authors contributed to the formatting and editing of the manuscript. All authors read and approved the final manuscript.

Competing interests

All authors declare that they have no competing interests.

\section{Appendix}

The brief description of sustainability labeling provided to the participants in the survey is as follows:

Sustainability labeling is:

- A labeling system to inform consumers of a product that meets sustainable performance criteria or specified standards.

- Sustainable practices may include, but are not limited to, environmentally friendliness and fair labor condition regarding ergonomic, worker, health and safety issues.

- Some examples include claims of being organic, being made with recycled materials, energy efficient, using renewable energy or fair trade.

- Some labels are certified by a qualified third-party.

Received: 5 November 2015 Accepted: 5 January 2017

Published online: 28 May 2017

\section{References}

Ajzen, I., \& Fishbein, M. (1980). Understanding attitudes and predicting social behavior. Englewood Cliffs: Prentice-Hall.

Al-Smadi, M. O. (2012). Factors affecting adoption of electronic banking: An analysis of the perspectives of banks' customers. International Journal of Business and Social Science, 3(17), 294-309.

Armstrong, J. S., \& Overton, T. S. (1977). Estimating nonresponse bias in mail surveys. Journal of Marketing Research, 14(3), 396-402.

Aspers, P. (2008). Labelling fashion markets. International Journal of Consumer Studies, 32(6), 633-638.

Bagozzi, R. P., \& Yi, Y. (1988). On the evaluation of structural equation models. Journal of the Academy of Marketing Science, 16(1), 74-94.

Baker, S. (2002). Hang tags: Connecting to consumers. http://www.just-style.com/analysis/connecting-to-consumers_ id93012.aspx. 
Beltramini, R. F. (1988). Perceived believability of warning label information presented in cigarette advertising. Journal of Advertising, 17(1), 26-32.

Benamati, J., \& Rajkumar, T. M. (2002). The application development outsourcing decision: An application of the technology acceptance model. Journal of Computer Information Systems, 42(4), 35-43.

Benamati, J., \& Rajkumar, T. M. (2008). An outsourcing acceptance model: An application of TAM to application development outsourcing decisions. Information Resource Management Journal, 21(2), 80-102.

Byrne, B. M. (2004). Testing for multigroup invariance using AMOS graphics: A road less traveled. Structural Equation Modeling, 11(2), 272-300.

Carrero, I., \& Valor, C. (2012). CSR-labelled products in retailers' assortment: A comparative study of British and Spanish retailers. International Journal of Retail \& Distribution Management, 40(8), 629-652.

Case, S. (2009). The future of green labels. http://govpro.com/green/content/green-label-value-200910-11.

Caswell, J. A. (1997). Uses of food labelling regulations. Paris: Organisation for Economic Co-operation and Development. http://www.oecd.org.

Chen, H. L., \& Burns, L. D. (2006). Environmental analysis of textile products. Clothing and Textiles Research Journal, 24(3), 248-261.

Catholic Online. 2014. Sweatshops strike back! Cambodia's garment industry roils with unhappy, underpaid workers. http:// www.catholic.org/news/international/asia/story.php?id=54176.

Cho, H., \& Wang, Y. (2010). Cultural comparison for the acceptance of online apparel customization. Journal of Consumer Marketing, 27(6), 550-557.

Cronbach, L. J. (1951). Coefficient alpha and the internal structure of tests. Psychometrika, 16(3), 297-334.

Davis, F. D. (1989). Perceived usefulness, perceived ease of use, and user acceptance of information technology. MIS Quarterly, 13(3), 319-340.

Davis, F. D., Bagozzi, R. P., \& Warshaw, P. R. (1989). User acceptance of computer technology: A comparison of two theoretical models. Management Science, 35(8), 982-1003.

De Boer, J. (2003). Sustainability labelling schemes: The logic of their claims and their functions for stakeholders. Business Strategy and the Environment, 12(4), 254-264.

Dickson, M. A. (2001). Utility of no sweat labels for apparel consumers: Profiling label users and predicting their purchases. The Journal of Consumer Affairs, 35(1), 96-119.

Dillman, D. A., Smyth, J. D., \& Christian, L. M. (2009). Internet, mail, and mixed-mode surveys: The tailored design method. Hoboken: Wiley.

D'Souza, C. (2004). Ecolabel programmes: A stakeholder (consumer) perspective. Corporate Communications: An International Journal, 9(3), 179-188.

D'Souza, C., Taghian, M., \& Lamb, P. (2006). An empirical study on the influence of environmental labels on consumers. Corporate Communications: An International Journal, 11(2), 162-173.

Etsy, D., \& Winston, A. (2009). Green to gold. New Haven: Yale University Press.

Fishbein, M., \& Ajzen, I. (1975). Belief, attitude, intention, and behavior: An introduction to theory and research. Reading: Addison-Wesley.

Fornell, C., \& Larcker, D. F. (1981). Evaluating structural equation models with unobservable variables and measurement error. Journal of Marketing Research, 18(1), 39-50.

Francois-LeCompte, A., \& Roberts, J. A. (2006). Developing a measure of socially responsible consumption in France. Marketing Management Journal, 16(2), 50-66.

Gam, H. J., Ma, Y. J., \& Banning, J. (2014). Socially responsible apparel labels: Effects on fashionable shoppers. Family and Consumer Sciences Research Journal, 42(3), 292-305.

Gorsuch, R. L. (1983). Factor analysis (2nd ed.). Hillsdale: LEA.

Goswami, P. (2008). Is the urban Indian consumer ready for clothing with eco-labels? International Journal of Consumer Studies, 32(5), 438-446.

Goworek, H., Fisher, T., Cooper, T., Woodward, S., \& Hiller, A. (2012). The sustainable clothing market: an evaluation of potential strategies for UK retailers. International Journal of Retail \& Distribution Management, 40(12), 935-955.

Hair, J. F., Anderson, R. E., Tatham, R. L., \& Black, W. C. (1998). Multivariate data analysis (5 ${ }^{\text {th }}$ ed.). Saddle River: Prentice Hall.

Horne, R. E. (2009). Limits to labels: The role of eco-labels in the assessment of product sustainability and routes to sustainable consumption. International Journal of Consumer Studies, 33(2), 175-182.

Hu, L. T., \& Bentler, P. M. (1999). Cutoff criteria for fit indexes in covariance structure analysis: Conventional criteria versus new alternatives. Structural equation modeling: a multidisciplinary journal, 6(1), 1-55.

Hyllegard, K. H., Yan, R. N., Ogle, J. P., \& Lee, K. H. (2012). Socially responsible labeling: The impact of hang tags on consumers' attitudes and patronage intentions toward an apparel brand. Clothing and Textiles Research Journal, 30(1), 51-66.

Kim, J., \& Forsythe, S. (2008). Adoption of virtual try-on technology for online apparel shopping. Journal of Interactive Marketing, 22(2), 45-59.

Kim, J., Jin Ma, Y., \& Park, J. (2009). Are US consumers ready to adopt mobile technology for fashion goods? An integrated theoretical approach. Journal of Fashion Marketing and Management: An International Journal, 13(2), 215-230.

Kim, H., Lee, E. J., \& Hur, W. M. (2012). The normative social influence on eco-friendly consumer behavior: The moderating effect of environmental marketing claims. Clothing and Textiles Research Journal, 30(1), 4-18.

Kline, R. B. (2005). Principles and practice of structural equation modeling. New York: Guilford Press.

Kline, P. (2014). An easy guide to factor analysis. New York: Routledge.

Koos, S. (2011). Varieties of environmental labelling, market structures, and sustainable consumption across Europe: A comparative analysis of organizational and market supply determinants of environmental-labelled goods. Journal of Consumer Policy, 34(1), 127-151.

Kunz, G. I., \& Garner, M. B. (2011). Going global (2nd ed.). New York: Fairchild.

Ma, Y. J., Lee, H.-H., \& Goerlitz, K. (2016). Transparency of global apparel supply chains: Quantitative analysis of corporate disclosures. Corporate Social Responsibility and Environmental Management, 23(5), 308-318.

Marquardt, S. (2010). Sustainability is not an option -Sustainable textiles represent the future global marketplace. Apparel, 51(6), 28. 
Marsh, H. W., \& Hocevar, D. (1985). Application of confirmatory factor analysis to the study of self-concept: First-and higher order factor models and their invariance across groups. Psychological Bulletin, 97(3), 562.

Meyer, A. (2001). What's in it for the customers? Successfully marketing green clothes. Business Strategy and the Environment, 10(5), 317.

Meyers, L. S., Gamst, G., \& Guarino, A. J. (2006). Applied multivariate research: Design and interpretation. Thousand Oaks: CA, Sage.

Minney, S. (2011). Naked fashion: The new sustainable fashion revolution. Oxford: New Internationalist.

Mohr, L. A., Webb, D. J., \& Harris, K. E. (2001). Do consumers expect companies to be socially responsible? The impact of corporate social responsibility on buying behavior. The Journal of Consumer Affairs, 35(1), 45-72.

Morris, L. A., Hastak, M., \& Mazis, M. B. (1995). Consumer comprehension of environmental advertising and labeling claims. The Journal of Consumer Affairs, 29(2), 328-350.

Nelliyat, P. (2004). Socio-economic, environmental and clean technology aspects of textile industries in Tiruppur, South India. http://www.sasnet.lu.se/EASASpapers/12PrakashNelliyat.pdf.

Norberg, H. M., Maehle, N., \& Korneliussen, T. (2011). From commodity to brand: Antecedents and outcomes of consumers'label perception. Journal of Product \& Brand Management, 20(5), 368-378.

Nunnally, J. C., Bernstein, I. H., \& Berge, J. M. T. (1967). Psychometric theory (Vol. 226). New York: McGraw-Hill.

Pavlou, P. A. (2003). Consumer acceptance of electronic commerce: Integrating trust and risk with the technology acceptance model. International Journal of Electronic Commerce, 7(3), 101-134.

Peterson, H. H., Hustvedt, G. M., \& Chen, Y. J. K. (2012). Consumer preferences for sustainable wool products in the United States. Clothing and Textiles Research Journal, 30(1), 35-50.

Phau, I., \& Ong, D. (2007). An investigation of the effects of environmental claims in promotional messages for clothing brands. Marketing Intelligence \& Planning, 25(7), 772-788.

Pinho, J. C. M. R., \& Soares, A. M. (2011). Examining the technology acceptance model in the adoption of social networks. Journal of Research in Interactive Marketing, 5, 116-129.

Roberts, J. A. (1995). Profiling levels of socially responsible consumer behavior: A cluster analytic approach and its implications for marketing. Journal of Marketing Theory and Practice, 3(4), 97-117.

Rogers, E. M. (1983). Diffusion of innovations. New York: Free Press.

Shin, D. H., \& Kim, W. Y. (2008). Applying the technology acceptance model and flow theory to cyworld user behavior: Implication of the web2. 0 user acceptance. CyberPsychology \& Behavior, 11(3), 378-382.

Steiger, J. H. (2007). Understanding the limitations of global fit assessment in structural equation modeling. Personality and Individual Differences, 42(5), 893-898.

Tan, G. W. H., Ooi, K. B., Sim, J. J., \& Phusavat, K. (2012). Determinants of mobile learning adoption: An empirical analysis. The Journal of Computer Information Systems, 52(3), 82-91.

Targosz-Wrona, E. (2009). Ecolabelling as a confirmation of the application of sustainable materials in textiles. Fibres \& Textiles in Eastern Europe, 17(4), 21-25.

Vijayasarathy, L. R. (2004). Predicting consumer intentions to use on-line shopping: The case for an augmented technology acceptance model. Information \& Management, 41(6), 747-762.

Wallace, S., Kench, B. T., \& Mihm, B. (2012). Coordination costs and firm boundaries: A tale of two supply chains in the apparel industry. Journal of Management Policy and Practice, 13(3), 47-65.

Walters, A., Santillo, D., \& Johnston, P. (2005). An overview of textiles processing and related environmental concerns. http://www.greenpeace.to/publications/textiles_2005.pdf.

Webster, F. E., Jr. (1975). Determining the characteristics of the socially conscious consumer. Journal of Consumer Research, 2(3), 188-196.

Wheaton, B., Muthen, B., Alwin, D., \& Summers, G. (1977). Assessing reliability and stability in panel models. Sociological Methodology, 8(1), 84-136.

Yi, Y., Wu, Z., \& Tung, L. L. (2006). How individual differences influence technology usage behavior? Toward an integrated framework. The Journal of Computer Information Systems, 46(2), 52-63. 